\title{
On the sea surface temperature high in the Lakshadweep Sea before the onset of the southwest monsoon
}

\author{
S. S. C. Shenoi, D. Shankar, and S. R. Shetye \\ National Institute of Oceanography, Goa, India
}

\begin{abstract}
The north Indian Ocean becomes the warmest area of the world oceans prior to the onset of southwest monsoon in June. During this period a zonal band of high sea surface temperature (SST), the "thermal equator" (TE), moves over this region concurrently with the Intertropical Convergence Zone (ITCZ). Using a weekly SST data set, we show that another SST high develops off southwest India in the Lakshadweep Sea in March, well before the TE moves in to the area, and that it continues to retain its identity until the onset of monsoon. The SST high has its genesis about 6 months earlier in the Bay of Bengal. The collapse of the southwest monsoon in October and the onset of the northeast monsoon trigger downwelling coastal Kelvin waves that propagate along the periphery of the Bay of Bengal, forcing an equatorward East India Coastal Current, which brings low-salinity water from the bay to the southeastern Arabian Sea during the northeast monsoon (November-January). As the Kelvin waves propagate poleward along the west coast of India after turning around Sri Lanka, they radiate downwelling Rossby waves that produce a "high" in sea level off southwest India. The downwelling and the surface layer of low-salinity water provide a breeding ground for the formation of a SST high in January. By March, with the increase in solar insolation due to the northward march of the Sun and the deep stable surface layer, the high reaches a mature phase clearly evident in the Lakshadweep Sea. By May, when the thermal equator and ITCZ move over the region, the high can be seen embedded in the TE. We speculate that at this time the high helps in producing conditions that are conducive for genesis of the monsoon onset vortex.
\end{abstract}

\section{Introduction}

Prior to the onset of the southwest monsoon, a pool of warm water covers a large area in the tropical Indian Ocean. Joseph [1990] called it the Indian Ocean warm pool because it is the warmest area of the world oceans during April and May. The warm pool forms a part of an approximately zonal band of high sea surface temperatures (SSTs) that we refer to as the thermal equator (TE). The TE is located near the equator in early February; the band, along with the Intertropical Convergence Zone (ITCZ), moves northward until June [Hastenrath and Lamb, 1979a; Rao et al., 1989], following movement of the Sun. The TE and the ITCZ form a significant component of a system that causes moisture convergence, which in turn leads to deep convection and clouds, heating of the tropospheric column above, strengthening of lower tropospheric winds, etc., all of which are a part of the monsoon onset that occurs over the southeastern Arabian Sea and southwestern India during the last week of May or first week of June.
The TE has its core in the Lakshadweep Sea (to the east of the Lakshadweep islands off southwest India, in the southeastern Arabian Sea), with temperatures greater than $30^{\circ} \mathrm{C}$ in the last week of May. This core forms off southwest India in February-March, well before the TE and the ITCZ move over the region. In this article we (1) show that the SST high off southwest India has an identity that is distinct from the TE and (2) examine the reasons for formation of the high SSTs in the Lakshadweep Sea.

Our hypothesis is that the high SSTs in the Lakshadweep Sea have their genesis about 6 months earlier in the Bay of Bengal. The hypothesis is motivated by two recent findings. The first is the discovery by Bruce et al. [1994] of a "high" in sea level that forms in the Lakshadweep Sea during the northeast monsoon (December-March). Using hydrography and altimetry, they described the high, which manifested as a large, anticyclonic eddy off southwest India at around $10^{\circ} \mathrm{N}$. We refer to this as the Lakshadweep high. The second finding is by Shankar and Shetye [1997]. They showed that (1) the high is a part of the annual cycle of events off south- 
west India, which includes the formation of the sea level high during the northeast monsoon and of a low during the southwest monsoon, and (2) the high and low are a result of Rossby wave radiation by coastal Kelvin waves that reach the west coast of India from the Bay of Bengal and the equatorial Indian ocean. The Kelvin waves that lead to the formation of the Lakshadweep high have their origins in the withdrawal and collapse of the southwest monsoon during August-October.

In the next section we examine the evolution of SSTs in the north Indian Ocean using the weekly SST fields for 1982-1995 compiled by Reynolds and Smith [1994]. The evolution of SST during January-June has a pattern similar to that of the evolution of the Lakshadweep high. In section 3 we examine the reasons for this similarity and conclude that the Lakshadweep Sea provides a favorable geographic setting for the rapid increase of SST. In section 4 we speculate on the role that the SST high might be playing in the formation of the monsoon onset vortex off southwest India.

\section{Evolution of SST in the Lakshadweep Sea During January-June}

Reynolds and Smith [1994] constructed an optimally interpolated weekly SST data set for 1982-1993 (subsequently extended to 1995 ) on a $1^{\circ} \times 1^{\circ}$ grid over the globe. In this study we have used their SSTs over the Indian Ocean. As suggested by Reynolds and Smith, a 1/4-1/2-1/4 binomial filter in time was applied to the SSTs before using them in our analysis.

A series of weekly SST fields during January-June 1989 is shown in Plate 1 to describe the evolution of SST in the Indian Ocean north of $20^{\circ} \mathrm{S}$. The most conspicuous feature seen in the first panel, for the week centered on January 1, 1989, is the band of high SST, the TE. The TE reflects the position of the Sun and hence of the region of maximum solar insolation. The ITCZ is associated with this region. The next panel in Plate 1, for the week centered on January 22, 1989, shows the TE as zonal patches of high SST. By the end of February the TE appears as two zonal bands of high SST, one around $15^{\circ} \mathrm{S}$ and the other farther north around $5^{\circ} \mathrm{S}$. In early March 1989 a blob of high SST, distinct from the TE, starts forming in the Lakshadweep Sea off southwest India. With time the blob grows toward west-southwest and, by the end of March, extends across the southern Arabian Sea. Simultaneously, the band of high SST associated with the TE, now a zonal belt $10^{\circ}-15^{\circ}$ latitude wide, migrates northward. In early April (around April 10, this year) the zonal band runs over the blob of high SST, but even then, the high SST blob retains its identity, maintaining a temperature of about $0.5^{\circ} \mathrm{C}$ higher than the surroundings.

We chose the period January-June 1989 because it demonstrates best the pattern of evolution of SST that we want to emphasize. There are two important characteristics of this pattern. First, the rate of warming in the Lakshadweep Sea is more than that in the surrounding areas. Second, and more important, this warming is not related to the movement of the TE because the blob of high temperature described above can be seen well separated from the TE. The evolution of SSTs in the region does not always follow the pattern shown in Plate 1. However, the two characteristics of the evolution can usually be seen; this is evident in Plate 2, which shows the evolution of SST in the climatology based on the 14-year data. The SST high is not seen as clearly in the climatology because of the averaging, but it does appear some distance offshore in March and as a broader patch in AprilMay. Table 1 lists the approximate dates of formation and disappearance of the blob of high SST during this 14-year period.

To examine further the warming in the Lakshadweep Sea and its association, or lack of it, with the TE, we computed the amplitude and phase of the annual harmonic of SST in the north Indian Ocean (Figure 1). The overall structure of the amplitude and phase is similar to that computed by Rao et al. [1989], who used the Comprehensive OceanAtmosphere Data Set (COADS). The SST field associated with the movement of the TE dominates the annual harmonic in the north Indian Ocean. The gradual change in phase from south (around $15^{\circ} \mathrm{S}$ in April) to north (around $20^{\circ} \mathrm{N}$ in late August) indicates the march of the SST field associated with the TE. In the Lakshadweep Sea the annual signal peaks during late April or early May, whereas farther west, in the central Arabian Sea, the annual signal peaks only in late June. Over the same latitudes in the Bay of Bengal also, the phase lags that in the Lakshadweep Sea. That the phase in the Lakshadweep Sea leads that over the surrounding areas indicates that the SST in the Lakshadweep Sea increases rapidly much

Table 1. Approximate Dates of Formation of the Sea Surface Temperature High, its Merger With the Thermal Equator, and Its Dissipation off Southwest India During 19821995. The SST high does not appear as a "blob" off southwest India in 1983, and hence no dates are given for this year.

\begin{tabular}{cccc}
\hline Year & Date of Formation & Merger & Dissipation \\
\hline 1982 & February 28 & April 11 & June 6 \\
1983 & $\ldots$ & $\ldots$ & $\ldots$ \\
1984 & March 25 & April 29 & May 27 \\
1985 & March 3 & April 7 & May 26 \\
1986 & March 2 & April 13 & June 1 \\
1987 & March 1 & April 26 & June 14 \\
1988 & January 24 & April 3 & May 29 \\
1989 & March 5 & April 9 & May 28 \\
1990 & February 11 & April 8 & May 27 \\
1991 & March 3 & April 14 & June 9 \\
1992 & March 8 & April 19 & June 18 \\
1993 & March 14 & April 25 & June 6 \\
1994 & March 20 & April 10 & June 5 \\
1995 & February 26 & April 9 & June 11 \\
\hline
\end{tabular}



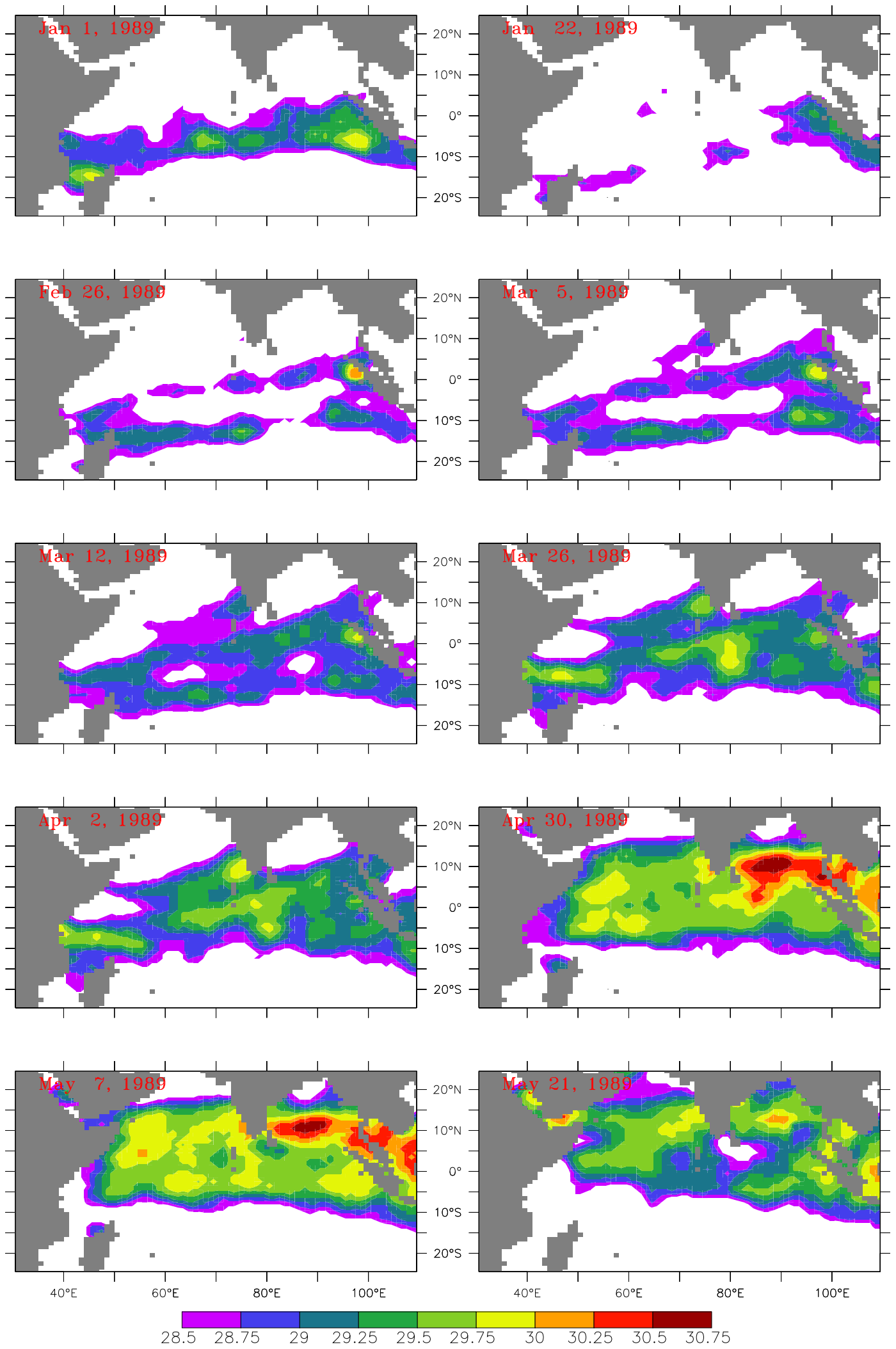

Plate 1. Evolution of weekly sea surface temperature (SST) during January-June 1989. The SST high first appears off southwest India in early March and retains its identity until the end of May, even though it merges with the thermal equator by the end of April. 

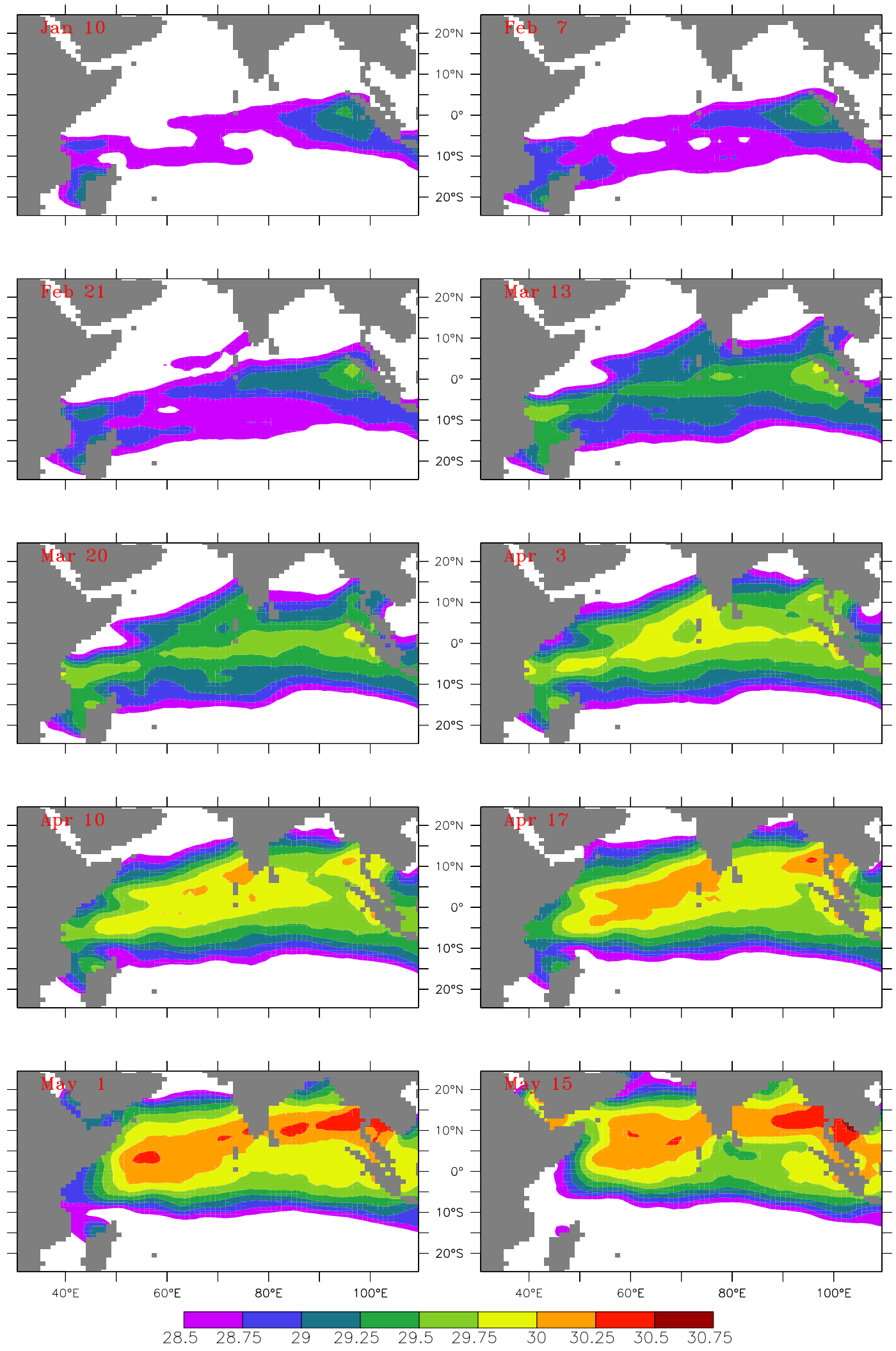

Plate 2. Evolution of climatological weekly SST during January-June. Though the SST high does not appear as clearly as in Plate 1 because of the averaging done over 14 years, a blob is seen some distance offshore in March and a broader patch is seen during April-May. 


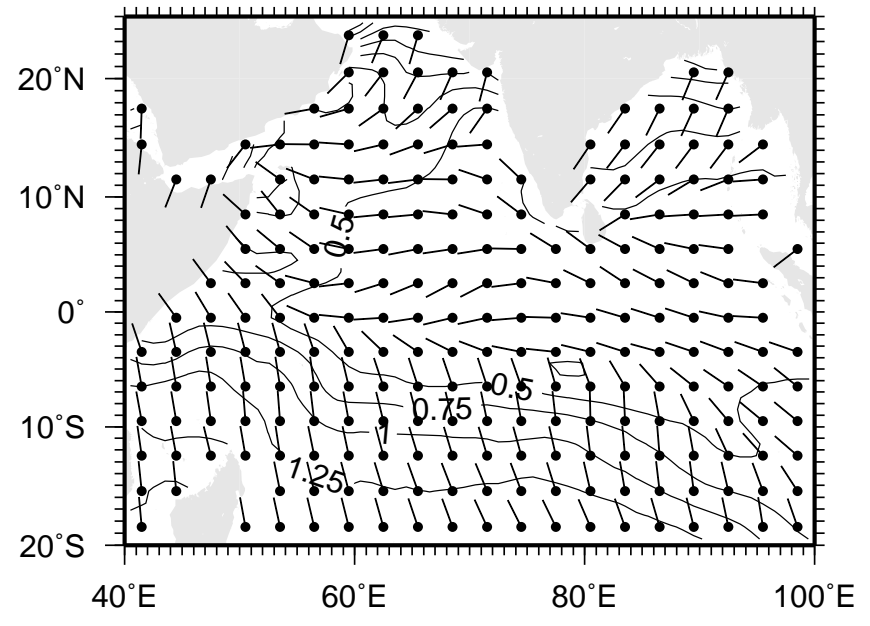

Figure 1. Amplitude and phase of the annual harmonic of the SST field. Contour interval is $0.25^{\circ} \mathrm{C}$; phase, measured anticlockwise from the east, is zero on January 1 , and $360^{\circ}$ covers 1 year. The gradual change in phase from south to north marks the progress of the thermal equator (TE). The phase off southwest India, however, leads the surrounding region and peaks in April, before the arrival of the TE over the southeastern Arabian Sea in late May.

before it does elsewhere in the Arabian Sea. This opens the possibility that the processes that drive the evolution of SST here are different from those that control the evolution of SST in the region of the TE.

\section{Lakshadweep Sea During the Northeast Monsoon}

What might be the processes that make the evolution of SST in the Lakshadweep Sea different from the evolution of SST in the surrounding area during January-June? Two processes can be held responsible for the local warming in the Lakshadweep Sea. First, the localized effects of air-sea fluxes, such as low latent heat flux, high solar radiation, etc.; second, the near-surface circulation and stratification in the region during the northeast monsoon. In this section we examine both processes.

\subsection{Air-Sea Fluxes}

To examine the distribution of air-sea fluxes, we have constructed the maps of latent heat flux and net shortwave radiation at the sea surface using National Center for Environmental Prediction/ National Center for Atmospheric Research (NCEP/NCAR) reanalysis climatology for 19821993 [Kalnay et al., 1996]. If latent heat flux and net shortwave radiation are responsible for the warming in the Lakshadweep Sea, then the distribution of these fluxes should show a low or high in the Lakshadweep Sea, which should be distinct from other areas. Figures 2 and 3 show the dis- tribution of latent heat flux and net shortwave radiation, respectively, for 1989. During the northeast monsoon, latent heat flux is high over northwestern Arabian Sea and the Bay of Bengal; it is low over southeastern Arabian Sea because of weak winds. During January-February a patch of low latent heat flux extends toward the equator from the southwest coast of India; it, however, starts disintegrating in March. By April the southeastern Arabian Sea, including the Lakshdweep Sea, experiences higher latent heat flux. A comparison of the patch of low latent heat flux in the southeastern Arabian Sea and the blob of high SST, shown in Plate 1, suggests a mismatch in the time of occurrence. The patch of low latent heat occurs in the southeastern Arabian Sea in January-February, but the blob of high SST appears there in early March, when the patch of low latent heat flux has started disintegrating. The blob of high SST strengthens and continues to exist at the same location during April, while the latent heat flux increases. Hence it is unlikely that the localized effect of latent heat flux causes the high SST observed in the Lakshadweep Sea.

Similarly, Figure 3 shows that the net shortwave radiation is high off the Indian west coast in February, but this high is spread over a much larger area and is not confined to the Lakshadweep Sea. During March-April, too, there is no localized high in the net shortwave radiation in the region; hence it appears that the net shortwave radiation also cannot be the cause of the SST high in the Lakshadweep Sea.

In the NCEP/NCAR data set the latent heat flux and shortwave radiation are classified as type $\mathrm{C}$ variables, which means that the in situ observations have very little influence on their distribution. Hence, to confirm the above conclusions, the monthly climatology maps of latent heat flux and net shortwave radiation (on $1^{\circ} \times 1^{\circ}$ grid) presented by Hastenrath and Lamb [1979b] were examined. They also do not show the pockets of low latent heat flux or of high net shortwave radiation over the Lakshadweep Sea. Therefore it appears that the air-sea fluxes are not the primary cause of the SST high in the Lakshadweep Sea.

\subsection{Near-Surface Circulation and Stratification}

Satellite altimetry shows that a high in sea level forms in the Lakshadweep Sea during the northeast monsoon and that a low forms during the southwest monsoon [Nerem et al., 1994; Tapley et al., 1994]. In hydrography [Bruce et al., 1994; Wyrtki, 1971] the high manifests as an anticyclonic eddy. A geostrophic current flows anticyclonically around the high; it bifurcates at the Indian coast, one branch flowing poleward and the other turning equatorward to complete the circulation around the high. This current is a continuation of the East India Coastal Current (EICC), which flows equatorward from October-January [McCreary et al., 1993; Shetye et al., 1996]. The presence of the Lakshadweep high splits the West India Coastal Current (WICC), which flows poleward in the north and equatorward in the south. These currents transport, from the Bay of Bengal to the Arabian Sea, the low-salinity waters that form a layer at the surface. 

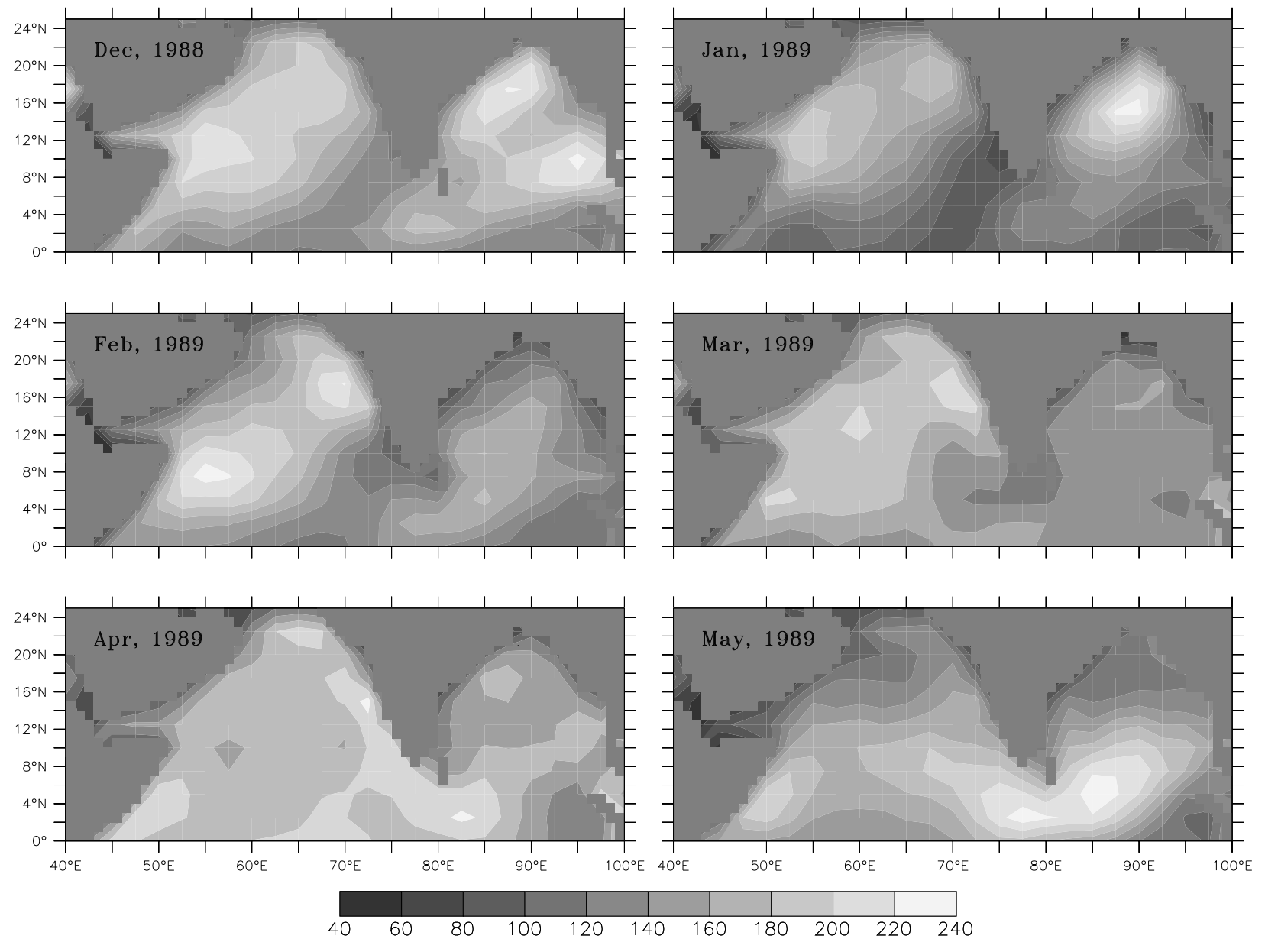

Figure 2. Distribution of latent heat flux $\left(\mathrm{W} \mathrm{m}^{-2}\right)$ on a $2.5^{\circ} \times 2.5^{\circ}$ grid based on the monthly mean of National Center for Environmental Prediction/ National Center for Atmospheric Research (NCEP/NCAR) reanalysis data set [Kalnay et al., 1996].

Salinity, in fact, is a useful tracer to mark this current (Figure 4).

It turns out that the EICC, the structure of the WICC, and the Lakshadweep high and low are all dynamically linked and are responsible for determining the oceanic conditions in the southeastern Arabian Sea. Shankar and Shetye [1997] examined the dynamics of circulation in this region using an analytical model and with numerical simulations with a one-and-half-layer dynamical reduced-gravity model. The model ocean, with an intial active layer thickness of $100 \mathrm{~m}$, was forced by the monthly mean wind stress climatology of Hellerman and Rosenstein [1983] (see Shankar and Shetye [1997] for model details). It was found that the downwelling (upwelling) Rossby waves that are radiated by downwelling (upwelling) coastal Kelvin waves propagating poleward along the Indian west coast are instrumental in generating the high (low) observed in the Lakshadweep Sea; a high forms shortly after December, and a low forms in July. Only Kelvin waves with a period greater than about 40 days contribute to the formation of the high and low. The Kelvin waves have a downwelling peak in December and an upwelling peak in July. Downwelling (upwelling) pushes down (up) the thermocline, causing deepening (shoaling) of the upper layer; increase (decrease) in upper layer thickness implies higher (lower) sea level. Figure 5 shows the variations in the thickness of the model upper layer; it is over $110 \mathrm{~m}$ thick in the Lakshadweep Sea. The simulation whose results are presented in Figure 5 differs from that of Shankar and Shetye [1997] in only one respect, namely that it includes the Lakshadweep and Maldive island chains. The inclusion of these island chains slows the westward progress of the high and low. Other than this, there are no appreciable changes from the results of Shankar and Shetye.

The Kelvin waves that radiate the Rossby waves off southwest India can either be generated by local winds blowing along the Indian west coast or be forced remotely. The 

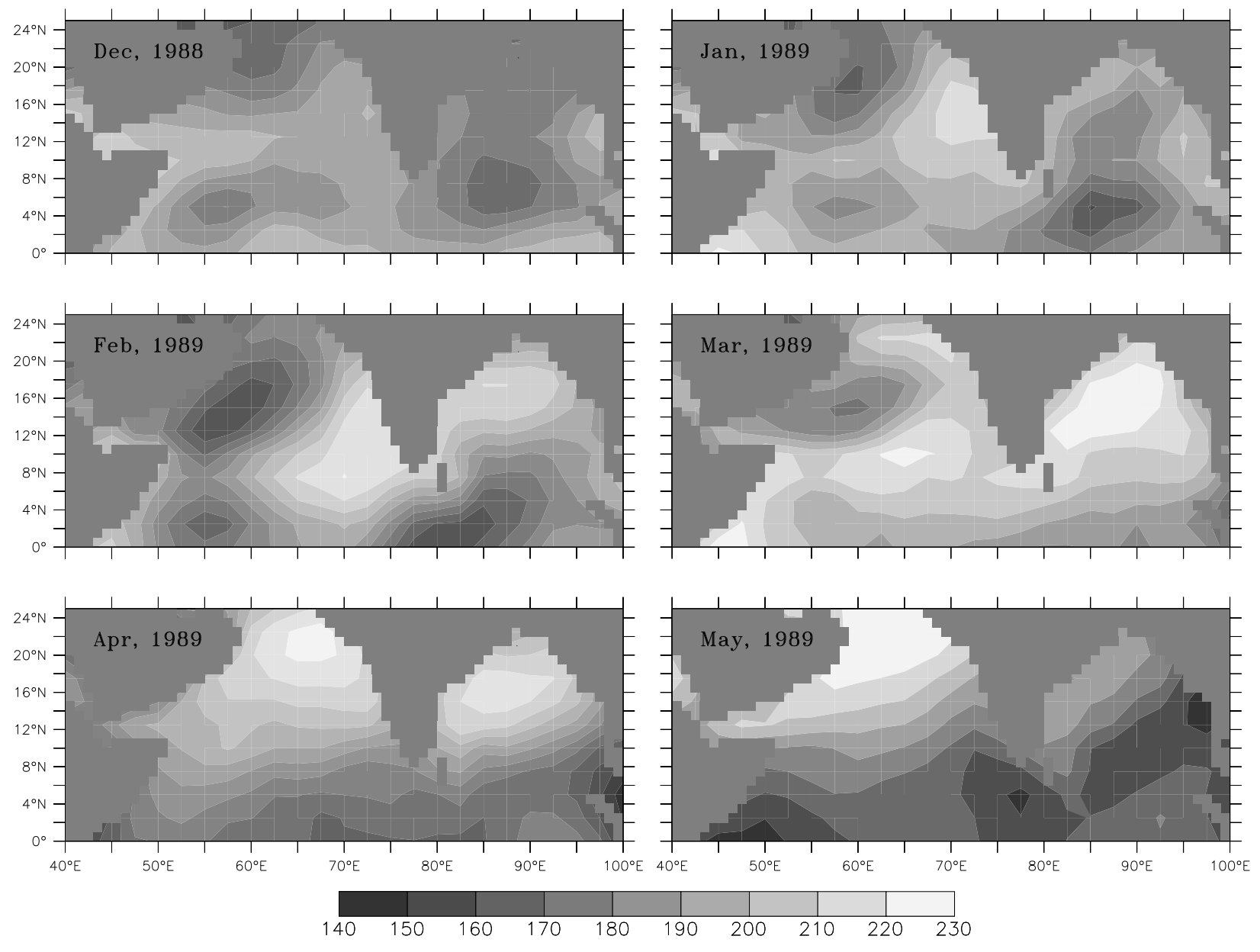

Figure 3. Distribution of net shortwave radiation $\left(\mathrm{W} \mathrm{m}^{-2}\right)$ at the surface on a $2.5^{\circ} \times 2.5^{\circ}$ grid based on the monthly mean of NCEP/NCAR reanalysis data set [Kalnay et al., 1996].

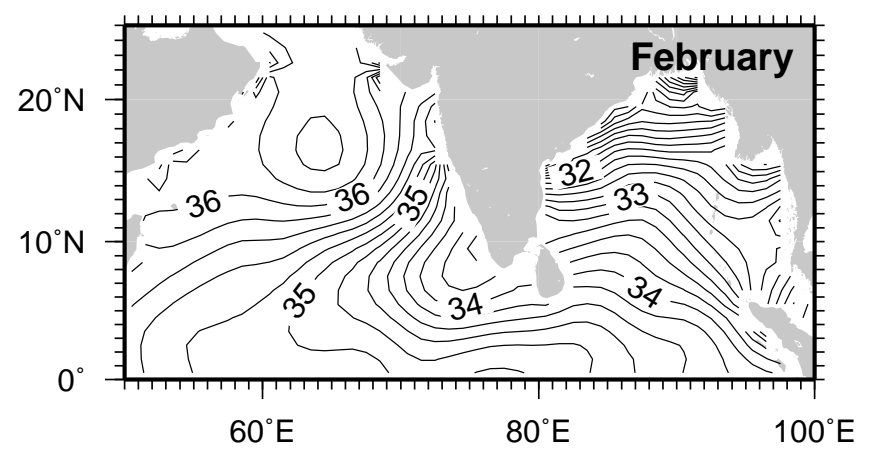

Figure 4. Horizontal distribution of surface salinity in February, based on the monthly mean climatology of Levitus et al. [1994]. The low salinity off southwest India is a result of inflow from the Bay of Bengal during November-January. remotely forced waves are generated by winds in the equatorial Indian Ocean [Yu et al., 1991] and by winds along the boundaries of the Bay of Bengal [McCreary et al., 1993]. These remotely generated Kelvin waves affect the EICC [McCreary et al., 1996] and, after bending around the southern tip of Sri Lanka, force changes in the WICC [McCreary et al., 1993; Shankar and Shetye, 1997]. Ekman pumping in the Lakshadweep Sea may also force the Rossby waves that form the Lakshadweep high. Model studies by Bruce et al. [1994, 1998] suggest that the negative wind stress curl in the region can also generate or enhance the Lakshadweep high. While all these mechanisms play a role in determining the circulation off southwest India, remote forcing is more significant, given that the winds off southwest India are much weaker than those in the bay or the equatorial Indian Ocean; also, the poleward WICC during the northeast monsoon flows against the prevailing winds [Shetye et al., 1991]. The model studies by McCreary et al. [1993] also support the conclusion that remote forcing is more significant in determining the circulation off southwest India. In 

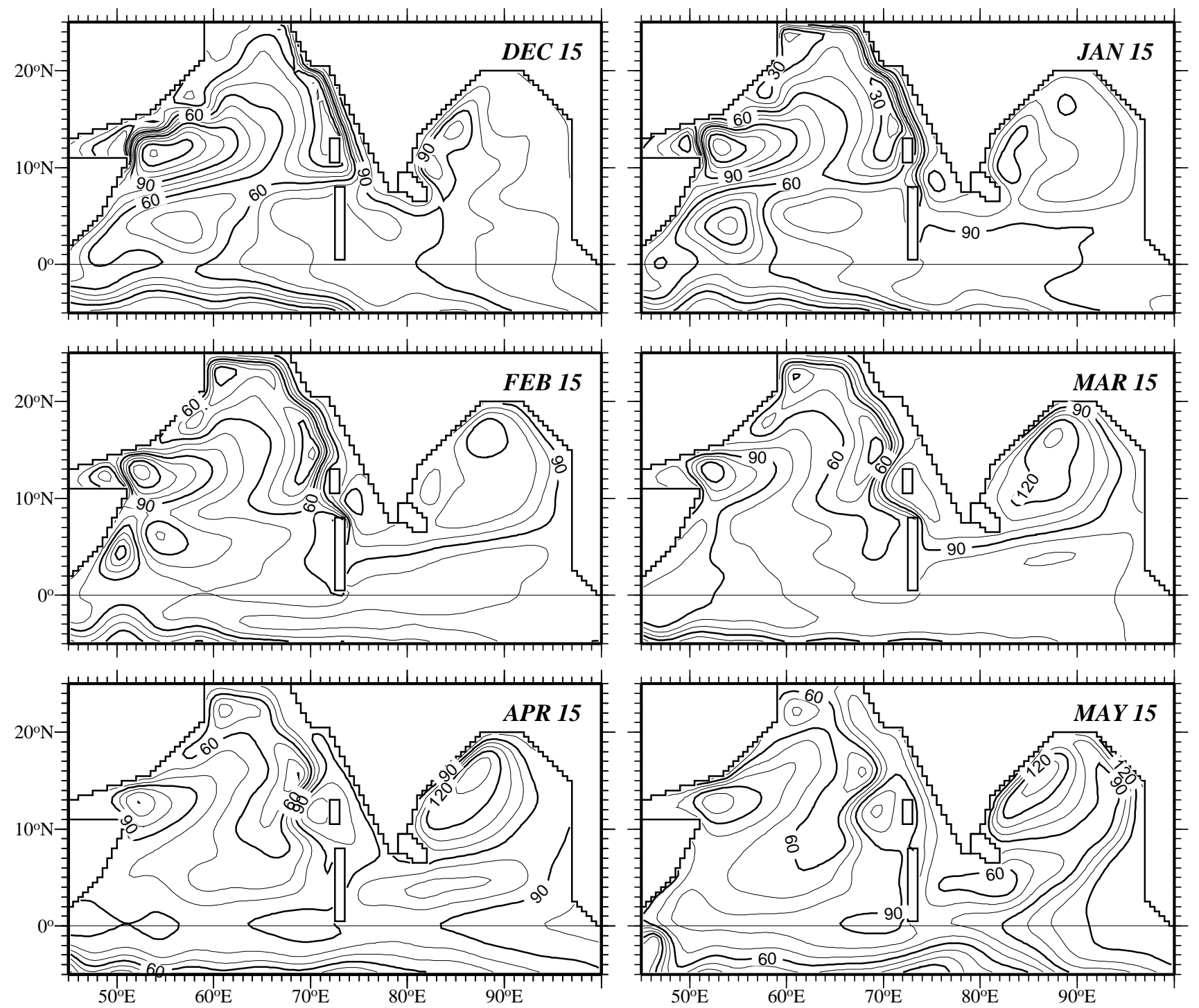

Figure 5. Upper layer thickness from a one-and-half-layer dynamical reduced-gravity model forced by the monthly mean wind stress climatology of Hellerman and Rosenstein [1983]. Contour interval is $10 \mathrm{~m}$. Thicker upper layer implies downwelling and a high in sea level. Downwelling Kelvin waves along the east coast of India turn around Sri Lanka and propagate along the west coast of India (see plot for December 15). They radiate westward propagating Rossby waves, and the Lakshadweep high forms off southwest India in January; it grows with time and moves westward. The high can still be seen in the vicinity of the Lakshadweep islands in May.

a test calculation without Arabian Sea winds, the currents along the west coast of India were still strong, but they were weaker without Bay of Bengal winds.

The equatorward EICC and the poleward WICC are also instrumental in bringing the low-salinity waters of the bay into the southern Arabian Sea. During the northeast monsoon the salinity in the Arabian Sea is above 34.5 while that in the Bay of Bengal is well below 34.0. The EICC transports about $7 \times 10^{6} \mathrm{~m}^{3} \mathrm{~s}^{-1}$ of water into the southern Arabian Sea, and at the same time, the Kelvin wave radiates Rossby waves, spreading the low-salinity waters more to- ward the west than toward the north, leading to the formation of a low-salinity pool off southwest India. The surface salinity distribution shown in Figure 4 clearly demonstrates the westward penetration of low-salinity water from the Bay of Bengal into the Arabian Sea. This can also be seen in the surface salinity distributions presented by Wyrtki [1971] for January-February. As a consequence of downwelling, the low-salinity water forms a surface layer approximately $60 \mathrm{~m}$ thick (Figure 6); below this layer, salinity increases sharply, creating a highly stable halocline.

The deep thermocline and the low-salinity layer lead to 


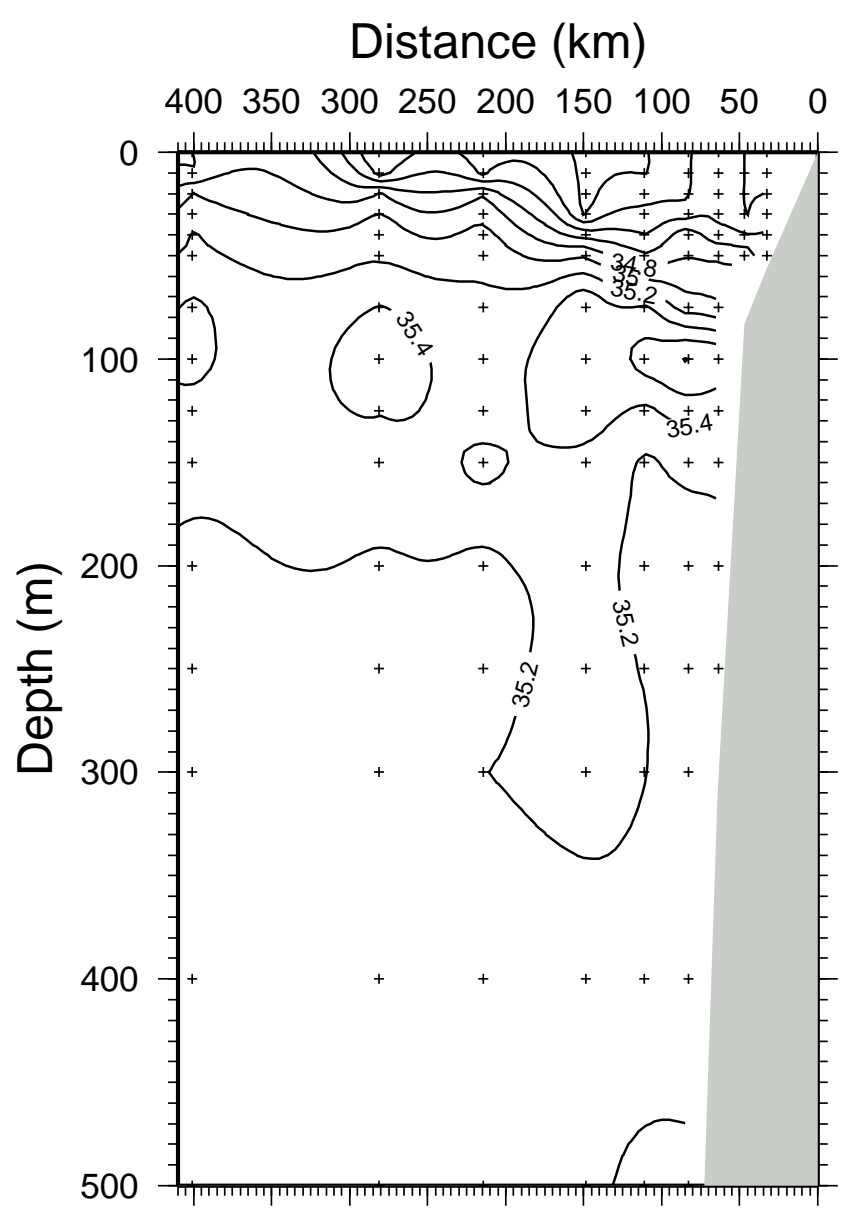

Figure 6. Vertical section of salinity during March-April 1994 along a leg that runs cross-shore (east-northeast to west-southwest) from around $10^{\circ} \mathrm{N}$ at the Indian west coast. Cross-shore distance from the coast is shown on the abscissa, and the crosses mark the standard depths used for contouring. The low-salinity surface layer and the sharp increase in salinity below it create a stable halocline.

stable near-surface stratification and thereby provide an ideal breeding ground for high SSTs. Given the closeness of the Lakshadweep Sea to the equator, solar radiation at the surface is never low; by the end of January, with the Sun having commenced its northward march, insolation begins to increase and the deep and stable upper layer permits a rapid increase in termperature. Hence the SST high in the Lakshadweep Sea forms even before the TE and the ITCZ move over the region.

With time the circular region of the thicker upper layer grows in size and moves westward (Figure 5) as did the SST high described earlier. In April the thickness of the layer drops to $80 \mathrm{~m}$ just to the east of the high. The shoaling of the upper layer on the eastern side indicates upwelling (due to the arrival of Kelvin waves with upwelling phase) and shoaling of the thermocline, which bring up the cooler subsurface waters, resulting in cooler SST near the coast. The juxtaposition of warm SSTs over the region of downwelling and cooler SSTs over the region of upwelling creates sharp SST gradients on the eastern flanks of the SST high.

In summary, the following is the chronology of events leading to formation of the high in SST in March-April. The collapse of the southwest monsoon winds trigger downwelling coastal Kelvin waves that propagate along the perimeter of the Bay of Bengal. The Kelvin waves, on reaching the western boundary of the bay, force an equatorward EICC, which turns around Sri Lanka and, on reaching the west coast of the Indian subcontinent, flows as a poleward WICC. The EICC and the WICC carry low-salinity waters from the bay to the Lakshadweep Sea during DecemberFebruary. The Kelvin waves along the west coast radiate downwelling Rossby waves, forming the Lakshadweep high. The downwelling and the low-salinity surface layer provide an ideal breeding ground for high SSTs (SSTs higher than $29^{\circ} \mathrm{C}$ ) in the Lakshadweep Sea as early as March. Toward the end of April the TE runs over this high, further enhancing its temperature; by the end of May the SST high becomes the core of a warm pool over the Arabian Sea and thereby the warmest spot in the region.

\section{Monsoon Onset Vortex}

The southwest monsoon is a complex phenomenon orchastrated by many processes. Expected to play a role in the phenomenon are unequal warming of land and ocean, dynamics and thermodynamics of the ITCZ, snow cover in the Himalayas, atmospheric fluctuations that girdle the tropical belt, the influence of El Niño and the Southern Oscillation, etc. Onset of the southwest monsoon rains over India is generally a spectacular event, very often preceded by the formation of an onset vortex. The vortex, an area of low pressure, forms around $10^{\circ} \mathrm{N}$ in the southeastern Arabian Sea. The low deepens to form a cyclonic storm, which results in establishment of a region of convergence over the southeastern Arabian Sea, followed by the strengthening of the monsoon westerlies. This leads to sustained rainfall over southwest India and heralds the onset of the southwest monsoon, hence the name "monsoon onset vortex." With the advance of the monsoon over India, the vortex also moves northward along the Indian west coast to about $20^{\circ} \mathrm{N}$ and then veers westnorthwestward. An exhaustive description of the occurrence of the vortex since 1901 is given by Ananthakrishnan et al. [1968], a summary of which is provided by Krishnamurti et al. [1981].

During the Monsoon Experiment (MONEX) in 1979 the vortex was observed to form after the low-level westerly flow had intensified. This prompted Krishnamurti et al. [1981] to propose that barotropic instability due to horizontal shear leads to formation of the vortex. Mak and Kao [1979] have suggested that vertical shear and stratification in the atmosphere are also responsible for genesis of the vortex. However, Douglas [1992] suggests that the onset vortex forma- 
5 The thermal equator and ITCZ move over the SST high by May-end, enhancing SST and causing large-scale moisture convergence. The high SSTs provide a necessary condition for the genesis of the monsoon onset vortex.

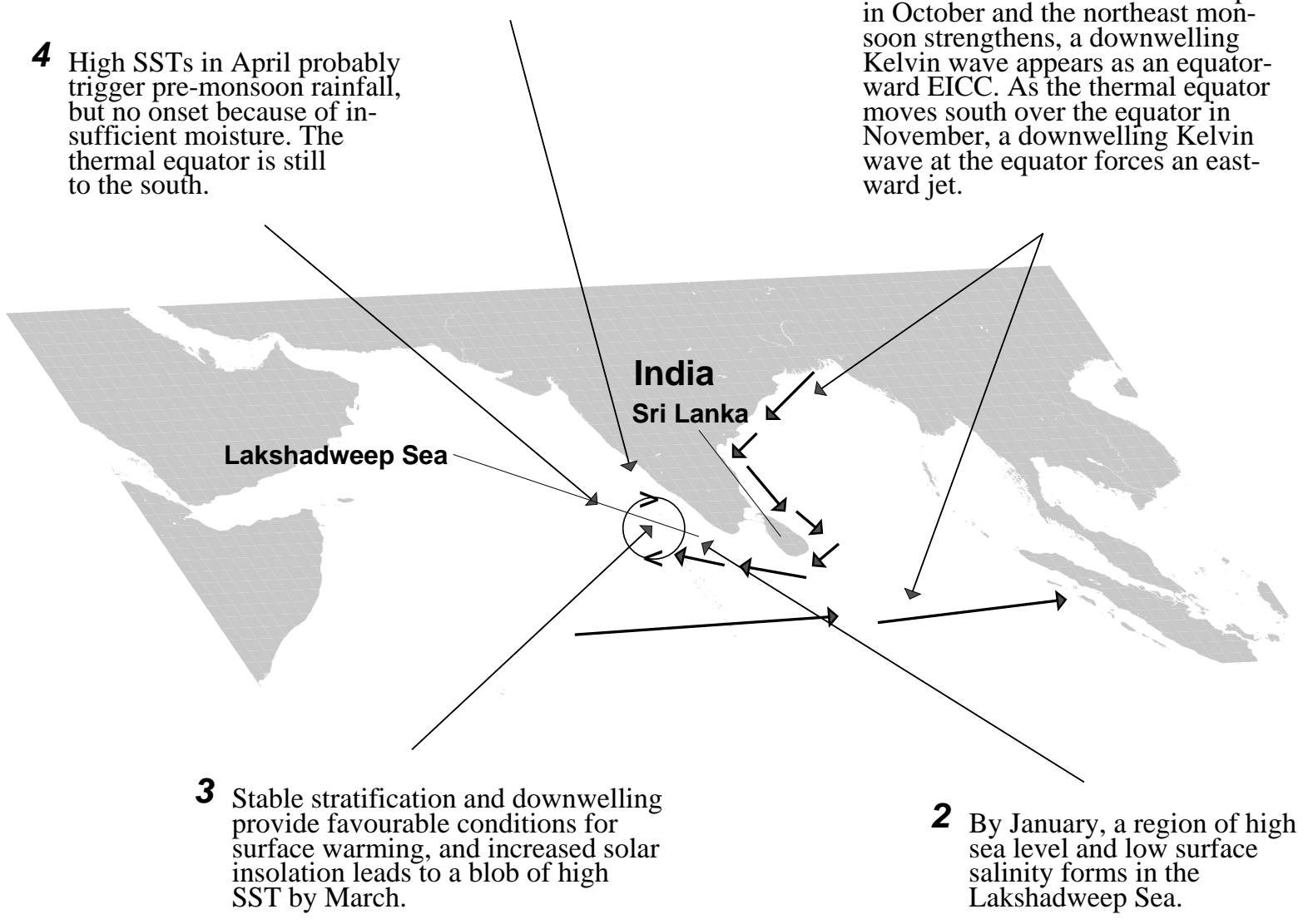

Figure 7. Schematic summarizing the process that leads to the formation of the premonsoon SST high and, perhaps, the monsoon onset vortex.

tion is a regional-scale response to a synoptic cyclonic circulation rather than the barotropic instability developed on the planetary-scale southwesterly monsoonal flow. Joseph [1990] has argued that the vortex is linked to the warm pool in the southeastern Arabian Sea. Does this mean that the SST high off southwest India causes the regional-scale response? There is no unequivocal answer to this question, at present. However, it is likely that the existence of all three, the Lakshadweep high, the SST high, and the onset vortex, in the same region is more than a mere coincidence.

What makes this possibility intriguing is that it seems to contain the elements of a classical coupled ocean-atmosphere system as follows: (1) An atmospheric event well separated from the eventual region of intense activity triggers events in the ocean; the collapse of the southwest monsoon in October and the onset of the northeast monsoon generate Kelvin waves in the Bay of Bengal. (2) Response entirely within the ocean produces special conditions at a location remote from the atmospheric event; the Kelvin waves from the bay lead to downwelling and to a stable surface layer in the Lakshadweep Sea, permitting high SSTs there. (3) The ocean provides necessary/favorable conditions to trigger an event in the atmosphere; the high SSTs of the Lakshadweep Sea influence formation of the onset vortex. This series of events is summarized in Figure 7.

It appears that in addition to playing a possible role in triggering the onset of the southwest monsoon, the SST high in the Lakshadweep Sea has other implications. Joseph and Pillai [1988] showed that in mid-April, about 6 weeks before the monsoon onset in late May or early June, the southwest coast of India experiences a spell of premonsoon rainfall. This event has all the signatures of a monsoon onset, except that it fizzles out quickly. Our speculation (based on personal communication (1997) from P. V. Joseph) is that the high SSTs in the Lakshadweep Sea play a role in this, too. However, sustained precipitation is not possible at this time 
because there is not enough moisture available; there is a competing source of high SST and low surface pressure created by the TE and the ITCZ farther south. By late May the TE and the ITCZ move over the Lakshadweep Sea, forming the Indian Ocean warm pool and lowering surface pressure off southwest India. This favors large-scale convergence, and moisture becomes available, creating conditions favorable for the formation of the monsoon onset vortex. This suggest that the Lakshadweep SST high probably provides a necessary, but not sufficient condition for the genesis of the monsoon onset vortex.

Acknowledgments. We thank P. V. Joseph for several discussions and R. W. Reynolds for the weekly SST data. The software packages FERRET and GMT were used extensively. G. S. Michael helped with the figures. Comments from three anonymous referees helped greatly in improving the manuscript. This work was carried out under projects sponsored by the Department of Science and Technology and the Department of Ocean Development, Government of India. This is NIO contribution 2602.

\section{References}

Ananthakrishnan, R., V. Srinivasan, A. R. Ramakrishnan, and R. Jambunathan, Synoptic features associated with onset of southwest monsoon over Kerala, Forecasting Manual, FMU Rep. IV-18.2, India Meteorol. Dept., Poona, 1968.

Bruce, J. G., D. R. Johnson, and J. C. Kindle, Evidence for eddy formation in the eastern Arabian Sea during the northeast monsoon, J. Geophys. Res., 99, 7651-7664, 1994.

Bruce, J. G., J. C. Kindle, L. H. Kantha, J. L. Kerling, and J. F. Bailey, Recent observations and modelling in the Arabian Sea Laccadive high region, J. Geophys. Res., 103, 7593-7600, 1998.

Douglas, M. W., Structure and dynamics of two monsoon depressions, I, Observed structure, Mon. Weather Rev., 120, 15241547, 1992.

Hastenrath, S., and P. J. Lamb, Climatic Atlas of the Indian Ocean, Part I, Surface Climate and Atmospheric Circulation, 97 charts, 19 pp., Wisconsin Univ. Press, Madison, 1979a.

Hastenrath, S., and P. J. Lamb, Climatic Atlas of the Indian Ocean, Part II, The Oceanic Heat Budget, 84 charts, 93 pp., Wisconsin Univ. Press, Madison, 1979b.

Hellerman, S., and M. Rosenstein, Normal monthly wind stress over the world ocean with error estimates, J. Phys. Oceanogr., 13, 1093-1104, 1983.

Joseph, P. V., Warm pool over the Indian Ocean and Monsoon Onset, Trop. Ocean Atmos. Newslett., 53, 1-5, Coop. Inst. for Mar. Atmos. Studies, Miami, 1990.

Joseph, P. V., and P. V. Pillai, 40-day mode of equatorial trough for long range forecasting of Indian summer monsoon onset, Curr. Sci., 57, 951-954, 1988.

Kalnay, E. et al., The NCEP/NCAR 40-year reanalysis project, Bull. Am. Meteorol. Soc., 77, 437-471, 1996.

Krishnamurti, T. N., P. Ardanuy, Y. Ramanathan, and R. Pasch, On the onset vortex of the summer monsoon, Mon. Weather Rev., 109, 344-363, 1981.
Levitus, S., R. Burgett, and T. P. Boyer, World Ocean Atlas 1994, vol. 3, Salinity, NOAA Atlas NESDIS 3, 99 pp., U.S. Govt. Print. Off., Washington, D.C., 1994.

Mak, M., and J. C. Y. Kao, An instability study of the onset-vortex of southwest monsoon, 1979, Tellus, 34, 358-368, 1982.

McCreary, J. P., P. K. Kundu, and R. L. Molinari, A numerical investigation of dynamics, thermodynamics and mixed-layer processes in the Indian Ocean, Prog. Oceanogr., 31, 181-224, 1993.

McCreary, J. P., W. Han, D. Shankar, and S. R. Shetye, Dynamics of the East India Coastal Current, 2, Numerical solutions, $J$. Geophys. Res., 101, 13,993-14010, 1996.

Nerem, R. S., E. J. Schrama, C. J. Koblinsky, and B. D. Beckley, A preliminary evaluation of ocean topography from the TOPEX/POSEIDON mission, J. Geophys. Res., 99, 24,56524583, 1994.

Rao, R. R., R. L. Molinari, and J. F. Festa, Evolution of the climatological near surface thermal structure of the tropical Indian Ocean, 1, Description of mean monthly mixed layer depth, sea surface temperature, surface current, and surface meteorological fields, J. Geophys. Res., 94, 10,801-10,815, 1989.

Reynolds, R. W., and T. M. Smith, Improved global sea surface temperature analysis using optimum interpolation, J. Clim., 7, 929-948, 1994.

Shankar, D., and S. R. Shetye, On the dynamics of the Lakshadweep high and low in the southeastern Arabian Sea, J. Geophys. Res., 102, 12,551-12,562, 1997.

Shetye, S. R., A. D. Gouveia, S. S. C. Shenoi, G. S. Michael, D. Sundar, A. M. Almeida, and K. Santanam, The coastal current of western India during the northeast monsoon, Deep Sea Res., Part A, 38, 1517-1529, 1991.

Shetye, S. R., A. D. Gouveia, D. Shankar, S. S. C. Shenoi, P. N. Vinayachandran, D. Sundar, G. S. Michael, and G. Nampoothiri, Hydrography and circulation in the western Bay of Bengal during the northeast monsoon, J. Geophys. Res.,101, 14,011-14,025, 1996.

Tapley, B. D., D. P. Chambers, C. K. Shum, R. J. Eanes, J. C. Ries, and R. H. Stewart, Accuracy assessment of the large-scale dynamic ocean topography from TOPEX/POSEIDON altimetry, $J$. Geophys. Res., 99, 24,605-24,617, 1994.

Wyrtki, K., Oceanographic Atlas of the International Indian Ocean Expedition, 531 pp., Natl. Sci. Found., Washington, D.C., 1971.

Yu, L., J. J. O'Brien, and J. Yang, On the remote forcing of the circulation in the Bay of Bengal, J. Geophys. Res., 96, 20,44920,454, 1991.

D. Shankar, S. S. C. Shenoi, S. R. Shetye, Physical Oceanography Division, National Institute of Oceanography, Dona Paula, Goa 403 004, India. (e-mail: shenoi@darya.nio.org)

Received October 2, 1997; revised September 29, 1998; accepted November $18,1998$.

This preprint was prepared with AGU's LATEX macros v5.01, with the extension package 'AGU ${ }^{++}$' by P. W. Daly, version 1.6b from 1999/08/19. 